\title{
THE ASSOCIATION BETWEEN GLUCOSE EXPOSURE AND THE RISK OF PERITONITIS IN PERITONEAL DIALYSIS PATIENTS
}

\author{
Anouk T.N. van Diepen, ${ }^{1}$ Sadie van Esch, ${ }^{2}$ Dirk G. Struijk, ${ }^{1,3}$ and Raymond T. Krediet ${ }^{1}$ \\ Division of Nephrology, ${ }_{1}^{1}$ Academic Medical Center, University of Amsterdam, Amsterdam, The Netherlands; \\ St. Elisabeth Hospital, ${ }^{2}$ Department of Nephrology and Internal Medicine, Tilburg, The Netherlands; \\ and Dianet, ${ }^{3}$ Amsterdam-Utrecht, The Netherlands
}

\begin{abstract}
- Background and objective: Little or no clinical evidence is available on the association between glucose exposure and peritoneal host defense in peritoneal dialysis (PD) patients. The objective of the present study was to quantify the exposure to glucose during the first year on PD and investigate the association with subsequent peritonitis.

- Methods: We analyzed prospectively collected demographic and peritonitis data from incident adult PD patients between 1990 and 2010. For the present study, we conducted a review of both in- and outpatient medical records of all patients to obtain their day-to-day dialysis schemes during the first year on PD. From these data, the average exposure to glucose was quantified. The exposure was stratified into low- and high-glucose groups based on the median, analyzed per standard deviation and in quartiles. Cox proportional hazard models were used to calculate crude and adjusted hazard ratios (HRs) and 95\% confidence intervals for the association between glucose exposure and peritonitis. Adjustments were made for age, sex, primary kidney disease, diabetes mellitus, Davies comorbidity score and the treatment period.
\end{abstract}

- Results: In total, 230 patients were included in the study of whom $151(66 \%)$ experienced a first peritonitis episode. The median follow-up time was $\mathbf{2 . 6}$ years (interquartile range [IQR]: $1.9-3.8$ ) in the low-glucose group and 3.1 (IQR: 2.1 - 4.2) in the high-glucose group. After adjustment for confounding factors, no association between high glucose exposure and the risk of peritonitis was found (HR: $0.81 ; 0.55-1.17$ ). No association was present when glucose exposure was analyzed per standard deviation (SD) (HR: $0.98 ; 0.79-1.21$ ) or patient quartiles were applied. No association was identified between glucose exposure and severe peritonitis, Staphylococcus aureus peritonitis, or a peritonitis episode that lasted more than 14 days.

- Conclusions: Exposure to glucose is not associated with an increased risk of peritonitis. The equilibrium between glycemic harm to peritoneal host defense and detrimental effects of glucose on invading microorganisms may determine the susceptibility to peritoneal infection.

Perit Dial Int 2016; 36(5):533-539 epub ahead of print: 04 Apr 2016 http://dx.doi.org/10.3747/pdi.2014.00318

Correspondence to: Anouk T.N. van Diepen, Academic Medical Center, University of Amsterdam, Meibergdreef 9, P0 Box 22660, 1100DD Amsterdam, The Netherlands.

a.t.vandiepen@amc.uva.nl

Received 10 December 2014; accepted 10 0ctober 2015.

Supplemental material available at www.pdiconnect.com
KEY WORDS: Peritoneal dialysis; glucose exposure; peritonitis; host defense.

ong-term exposure to dialysis solutions causes strucLtural changes to the peritoneum in peritoneal dialysis (PD) patients (1). The unphysiological composition of the dialysate has been hypothesized to compromise peritoneal host defense. Many in vitro, ex vivo and animal studies have been performed to investigate this hypothesis $(2-5)$. These studies point to the detrimental effects of acidic $\mathrm{pH}$, glucose, hyperosmolality, lactate buffer, and glucose degradation products (GDPs) on monocytes, peritoneal macrophages, neutrophils, and mesothelial cells. However, the majority of these studies cannot be translated to the clinical situation due to a lack of follow-up, non-realistic exposure levels, or the absence of renal failure. Over the last decade, multiple randomized controlled trials (RCTs) have been performed to compare the incidence of peritonitis between patients randomized to a high- or low-GDP regimen (6-15) and, when meta-analyzed, found no difference (16). Bicarbonate buffering reduced the length of time to peritonitis in a RCT (17), but these results still need to be confirmed in other populations. Indirectly, RCTs that compared icodextrin with glucose for the long dwell investigated a glucose-sparing vs a non-glucose-sparing regimen and reported no difference in peritonitis episodes between the 2 arms (18-21). Therefore, the composition of the dialysate appears to be harmful in non-clinical experiments, but clinical studies demonstrate otherwise.

None of the clinical studies that investigated glucose exposure and the incidence of peritonitis quantified the exposure to glucose and assessed a dose-response relationship. Furthermore, the literature concerning quantification of glucose exposure used calculations that can only be applied to continuous ambulatory PD (CAPD) patients and provide very rough estimates of the actual glucose exposure $(22,23)$. Therefore, it is unknown whether the estimated glucose exposure is associated with an increased susceptibility to peritonitis in patients. The objective of the present study was to quantify the exposure to glucose during the first year on PD and to investigate the association with subsequent peritonitis. Our hypothesis was that exposure to higher concentrations of glucose is associated with an

This single copy is for your personal, non-commercial use only.

For permission to reprint multiple copies or to order presentation-ready

copies for distribution, contact Multimed Inc. at marketing@multi-med.com 
increased risk of peritonitis and a shorter time to the first peritonitis episode.

\section{MATERIALS AND METHODS}

\section{STUDY DESIGN}

The present study was conducted in a large prospective database of incident PD patients, aged $>18$ years, receiving dialysis in a Dutch tertiary-care university hospital between January 1990 and July 2010. All patients were treated with solutions obtained from Baxter Healthcare S.A. (Castlebar, Ireland). Data on baseline demographics and peritonitis episodes were collected prospectively in the database as part of routine clinical care. For the present study, we conducted a review of both inand outpatient medical records of all patients to obtain their prescribed day-to-day dialysis schemes during the first year on dialysis. Patients who remained less than 1 year on PD were excluded, because we could not obtain complete information about glucose exposure during their first year on PD. Patients with peritonitis during the first year on PD were excluded to avoid an effect of peritonitis on exposure. Time of follow-up was defined as the number of days between the first 365 days on PD and the date of censoring.

\section{DEMOGRAPHIC DATA COLLECTION}

Routinely collected demographic data at the start of PD included dialysis modality (CAPD/automated PD [APD]), age, sex, and primary kidney disease. Additional data collected during the review of medical records included diabetes mellitus, Davies comorbidity score (24), the use of an angiotensin-converting enzyme inhibitor (ACE), and the use of an angiotensin II receptor blocker (ARB). Because no data on 24-hour urine urea and creatinine were available, we used serum beta-2-microglobulin to estimate residual renal function. It is known from the literature that this parameter can be used to estimate residual glomerular filtration rate (25).

\section{GLUCOSE EXPOSURE}

Day-to-day dialysis schemes were retrospectively collected in a large database. Those between 0 and 180 days on PD were neglected because this is a period in which the PD scheme is often not stable, due to adjustments required by the patients' transport status and hydration state. On a day without information on the dialysis scheme, it was assumed that the scheme of the previous day was followed. Data collected about the dialysis schemes of CAPD patients included the number of dwells per day, dwell volume, glucose concentration, the dwell time, and the type of dialysis solution. Data collected for APD patients included the total treatment volume, total treatment time, number of cycles, tidal percentage, dwell volume and glucose concentration per cycle, and dwell volume and glucose concentration of the last bag. From these data, the average exposure to glucose during 24 hours between 180 and 365 days can be quantified. Three assumptions were made for the quantification of the glucose exposure: 1) Glucose absorption from the peritoneal cavity averages $60 \%$ after 4 hours (26); 2) glucose absorption follows first order kinetics, which means that it becomes linear after logarithmic transformation; 3 ) the geometric mean of glucose exposure in the middle of the dwell is the closest approximation of the average glucose exposure during the total dwell. The following calculation can be made for the geometric mean glucose concentration of a 4-h dwell: $\ln G_{m}=\ln \left(G_{i}\right)+\left(\ln \left(0.4 G_{i}\right)-\ln \left(G_{i}\right)\right) / 2$. In this equation $\ln G_{m}$ is the natural logarithm of the geometric mean glucose concentration, $G_{i}$ is the initial dialysate glucose concentration and 0.4 indicates that after 4 hours only $40 \%$ of the initial glucose concentration is present. The initial glucose concentration for $1.36 \%$ glucose is $70 \mathrm{mmol} / \mathrm{L}$, for $2.27 \%$ glucose is $118 \mathrm{mmol} / \mathrm{L}$ and for $3.86 \%$ glucose is $198 \mathrm{mmol} / \mathrm{L}$. Calculation of $\mathrm{G}_{\mathrm{m}}$ for any dwell time can be done using $e^{\ln G m}$. The average glucose exposure during 24 hours is the sum of all $G_{m}$ values of each dwell multiplied by the fractional duration of the dwell per 24 hours. Examples are given in Supplemental Appendix 1.

\section{STATISTICAL ANALYSES}

Baseline characteristics were stratified according to the median of the glucose exposure. Continuous data are expressed as mean values and standard deviations (SD) or median and interquartile ranges (IQR) as appropriate and categorical variables in proportions. Differences between baseline characteristics were tested with an unpaired Student's t-test, Mann-Whitney (continuous data), or chi-square test (categorical data). Unadjusted cumulative survival curves over a period of 5 years according to high and low glucose were calculated, with the first peritonitis episodes, death, switch to hemodialysis (HD), and transplantations as the events.

Cox proportional hazard models were used to calculate crude and adjusted hazard ratios (HRs) and 95\% confidence intervals (CI) for the association between glucose exposure and peritonitis. For these analyses, glucose exposure was stratified into high or low exposure based on the median, assessed per SD and in quartiles. Violation of the proportionality assumption in the Cox models was checked by making log-minus-log plots. No violations were observed. Adjustments were made for age, sex, primary kidney disease, diabetes mellitus, Davies comorbidity score, and the treatment period (1990 - 1996 (Dianeal; Baxter Healthcare SA, Castlebar, Ireland, only), 1997 - 2004 (transition period and introduction of icodextrin), 2005 2010 (Physioneal; Baxter Healthcare SA, Castlebar, Ireland only). Additional Cox proportional hazard models were used to calculate crude and adjusted HRs and 95\% CIs for the association between glucose exposure and severe Staphylococcus aureus or long-lasting peritonitis. For these analyses, glucose exposure was stratified into high or low exposure. Severe peritonitis was defined as a leukocyte count $>1,090$ cells/ $\mathrm{mm}^{3}$ on day 3 or $>100$ cells/ $\mathrm{mm}^{3}$ on day 5 of the peritonitis episode (27) and compared with patients without severe peritonitis. Causative microorganisms were dichotomized in 
Staphylococcus aureus and compared with patients who did not suffer from Staphylococcus aureus peritonitis. The duration of the peritonitis episode was calculated and dichotomized in long duration ( $>14$ days) and compared with patients who did not experience a first peritonitis episode that lasted longer than 14 days. All data analyses were performed using SPSS 20.0 (SPSS, Chicago, IL, USA) and STATA 12.1 (StataCorp LP, College Station, TX, USA).

\section{SENSITIVITY ANALYSES}

Sensitivity analyses with less strict inclusion criteria were performed to demonstrate whether the results could change when: 1) dialysis schemes were included from day 1 on PD; 2) a study baseline of 3 months or 6 months was used and consequently; 3 ) the majority of the first peritonitis episodes during the first year on PD could be included in the analysis. The influence of CAPD/APD on peritonitis risk is uncertain and therefore is a confounder $(28,29)$. A sensitivity analysis was performed, in which modality (CAPD/APD) at the start of dialysis was added to the fully adjusted model to explore its influence on the association. Residual renal function at the start of dialysis might be a confounder of the association. However, this information was available in a limited number of patients $(n=99)$. Therefore, residual renal function according to serum beta-2-microglubulin was added to the model in a sensitivity analysis to examine its impact on the association.

\section{RESULTS}

\section{POPULATION CHARACTERISTICS}

Medical records of 479 incident patients starting PD treatment between January 1990 and July 2010 in our center were reviewed. After excluding patients with incomplete or lost files $(n=39)$ or less than 1 year until peritonitis or censoring $(n=$ 210) a total of 230 patients could be included. The baseline characteristics of the study population are summarized in Table 1. The median and mean of the glucose exposure between 6 and 12 months was $44 \mathrm{mmol} / \mathrm{L}$ during 24 hours with a SD of 18. Patients with a higher glucose exposure were more often treated with CAPD and had lower residual renal function. The median follow-up time was 2.6 years (IQR: $1.9-3.8$ ) in the low-glucose group and 3.1 (IQR: 2.1 - 4.2) in the high-glucose group. Of all patients, 147 (64\%) experienced a first peritonitis episode, of which 77 were treated with low glucose exposure and 70 with high glucose exposure. The main reasons for censoring in patients without peritonitis were death (low glucose: 14\%; high glucose: $16 \%$ ) and transplantation (low glucose: 13\%; high glucose: $11 \%$ ) (Figure 1 ).

TABLE 1

Baseline Demographic Characteristics

\begin{tabular}{|c|c|c|c|}
\hline Characteristic & $\begin{array}{l}\text { 'Low exposure' } \\
\text { Glucose exposure } \\
<44 \mathrm{mmol} / \mathrm{L} / 24 \mathrm{~h}\end{array}$ & $\begin{array}{c}\text { 'High exposure' } \\
\text { Glucose exposure } \\
\geq 44 \mathrm{mmol} / \mathrm{L} / 24 \mathrm{~h}\end{array}$ & $P$ value \\
\hline No of patients (\%) & 115 & 115 & \\
\hline Age (median (IQR)) & $54(42-67)$ & $57(44-66)$ & 0.93 \\
\hline Sex (\% male) & 64 & 58 & 0.42 \\
\hline Diabetes (\%) & 29 & 33 & 0.48 \\
\hline Primary kidney disease (\%) & & & 0.14 \\
\hline Diabetic nephropathy & 24 & 29 & \\
\hline Glomerulonephritis & 18 & 24 & \\
\hline Renal vascular disease & 20 & 17 & \\
\hline Other & 37 & 30 & \\
\hline Davies comorbidity score (\% severe) & 9 & 8 & 0.85 \\
\hline Dialysis modality (\%) & & & 0.002 \\
\hline CAPD only & 41 & 72 & \\
\hline APD only & & 23 & 7 \\
\hline CAPD switched to APD & 33 & 17 & \\
\hline APD switched to CAPD & 4 & 4 & \\
\hline ACE/ARB usage (\%) & & & 0.17 \\
\hline ARB only & 4 & 4 & \\
\hline ACE only & 46 & 44 & \\
\hline$A C E+A R B$ & 12 & 5 & \\
\hline Serum $\beta-2$ microglobulin $(\mathrm{mg} / \mathrm{L})^{*}$ & $19.9 \pm 7.0$ & $23.4 \pm 8.8$ & 0.03 \\
\hline Glucose exposure (mmol/L/24 h; median (IQR)) & $27(21-33)$ & $51(46-61)$ & $<0.001$ \\
\hline Time on PD (years; median (IQR)) & $2.6(1.9-3.8)$ & $3.1(2.1-4.2)$ & 0.11 \\
\hline
\end{tabular}

$\mathrm{IQR}=$ interquartile range; $\mathrm{CAPD}=$ continuous ambulatory peritoneal dialysis; $\mathrm{APD}=$ automated peritoneal dialysis; $\mathrm{ACE}=$ angiotensin $\mathrm{I}$ converting enzyme inhibitor; $A R B=$ angiotensin II receptor blocker.

${ }^{*}$ At baseline and available in a limited number of patients $(n=99)$.

This single copy is for your personal, non-commercial use only. For permission to reprint multiple copies or to order presentation-ready 
Low glucose exposure

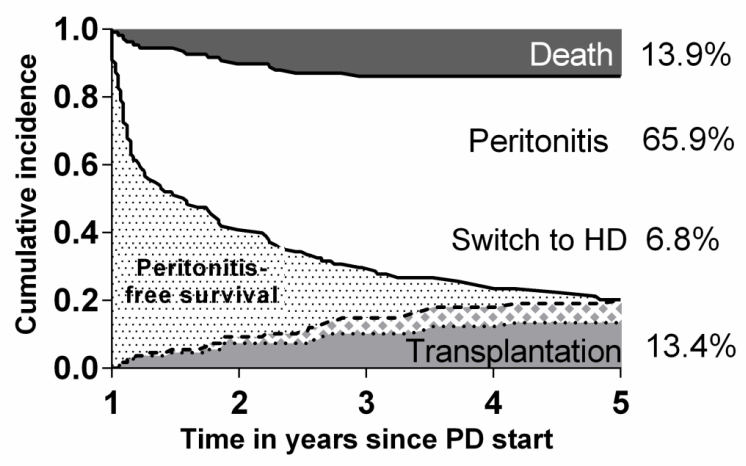

High glucose exposure

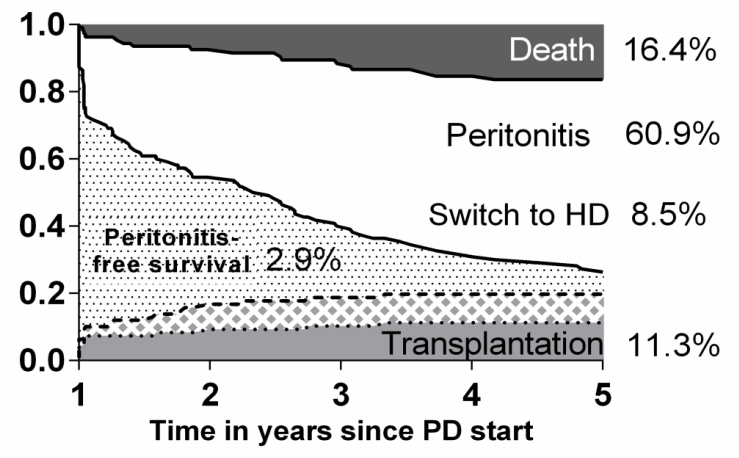

\begin{tabular}{ccccc}
365 & 730 & 1095 & 1460 & 1825 \\
\hline 115 & 84 & 51 & 25 & 3
\end{tabular}

Figure 1 - Unadjusted cumulative incidence survival curves for peritonitis-free survival, peritonitis, switch to HD, transplantation, and death on PD for patients exposed to low and high glucose exposure. HD = hemodialysis; PD = peritoneal dialysis; $d=$ days.

\section{GLUCOSE EXPOSURE AND PERITONITIS}

Figure 1 shows the unadjusted cumulative incidence survival curves. No difference in the crude peritonitis-free survival was observed between the patients exposed to high and low glucose. Table 2 shows crude and adjusted HRs and $95 \%$ CIs for high vs low glucose exposure, per glucose SD and in patient quartiles. The unadjusted HRs demonstrated a consistent trend that is suggestive of a protective association between higher glucose exposure and peritonitis. However, when adjustments for confounding factors were made, the trend toward an association lost statistical significance. High glucose exposure remained associated with a 19\% lower risk of peritonitis compared with low glucose exposure, but the CI was fairly wide and could indicate both a $45 \%$ decreased risk and a $17 \%$ increased risk of peritonitis in the high exposure group. Also, no association was present when glucose exposure was evaluated per SD or when patient quartiles were applied.

\section{SEVERITY, CAUSATIVE MICROORGANISM, AND DURATION OF THE PERITONITIS EPISODE}

Of all first peritonitis episodes, 74 lasted longer than 14 days, 26 could be qualified as a severe peritonitis episode, and in 25 of the cases, Staphylococcus aureus was the causative microorganism. Supplemental Appendix 2 shows the distribution of the causative microorganisms in the low and high glucose exposure groups. Unadjusted HRs were non-significant with a large confidence interval for severe peritonitis (HR: 0.71 ; 95\% CI: $0.46-1.10)$, Staphylococcus aureus peritonitis (0.83; $0.40-1.72)$, or a peritonitis episode that lasts more than 14 days $(0.71 ; 0.55-0.91)$. The low event rate of severe and Staphylococcus aureus peritonitis made further adjustments impossible. However, when adjustments were made, high glucose exposure might lead to a $14 \%$ decreased risk of a peritonitis episode that lasted more than 14 days, but the CI was fairly wide and remained non-significant $(0.86 ; 0.63-1.17)$.

\section{SENSITIVITY ANALYSES}

When less strict inclusion criteria were used, the results did not change when dialysis schemes were included from day 1 on PD and the study baseline was set at 3 months (adjusted HR high vs low glucose exposure: $0.87 ; 95 \%$ CI: $0.65-1.17$; adjusted HR per SD: $1.04 ; 95 \%$ CI: $0.89-1.21), 6$ months (adjusted HR high vs low glucose exposure: $0.73 ; 95 \% \mathrm{CI}$ : 0.51 - 1.06; adjusted HR per SD: 1.09 ; $95 \%$ CI: $0.86-1.38$ ) or 1 year (adjusted HR high vs low glucose exposure: $0.76 ; 95 \%$ CI: 0.47 - 1.22; adjusted HR per SD: $1.07 ; 95 \%$ CI: $0.84-1.36$ ). When dialysis modality (CAPD/APD) at the start of dialysis was added to the model, the HRs changed slightly, but were not significant with reasonably large CIs (high vs low HR: 0.84 ; 0.57 - 1.23; per SD HR: $1.01 ; 0.81-1.25)$. When residual renal function was added to the model, the HRs did not change.

\section{DISCUSSION}

We demonstrated a novel method for the quantification of glucose exposure that can be used in both CAPD and APD patients. The results of the present study show that glucose exposure during the first year on PD is not associated with the time to subsequent peritonitis. In addition, no association between the amount of glucose exposure and severe peritonitis, Staphylococcus aureus peritonitis, or a peritonitis episode that lasts more than 14 days was identified.

Our results are in line with the results from previous RCTs that compared peritonitis risk in patients treated with a glucose sparing with a non-glucose sparing regimen (18-21). They are, however, in contrast to a large body of evidence from in vitro, ex vivo, and in vivo studies (2-5). Two possible explanations for this phenomenon are presented. First, it might be that the experiments were unable to mimic the situation in PD patients. Experimental models often suffered from lack of follow-up, non-realistic exposure levels, or the absence of renal failure, which makes translation to clinical practice impossible. A 
TABLE 2

Crude and Adjusted HRs (95\% CI) Associated with Glucose Exposure During 6-12 Months on Peritoneal Dialysis

\begin{tabular}{|c|c|c|c|c|c|c|}
\hline & $\begin{array}{l}\text { HR }(95 \% \mathrm{CI}) \\
\text { glucose high vs } \\
\text { glucose low }\end{array}$ & $\begin{array}{c}\text { HR }(95 \% \text { CI }) \\
\text { per SD glucose }\end{array}$ & $\begin{array}{c}\text { Qrt1: } \\
0-27.0 \mathrm{mmol} / \mathrm{L} \\
\text { during } 24 \mathrm{~h}\end{array}$ & $\begin{array}{c}\text { Qrt2: } \\
\text { 27.1-41.0 mmol/L } \\
\text { during } 24 \mathrm{~h}\end{array}$ & $\begin{array}{c}\text { Qrt3: } \\
\text { 41.1-51.4 mmol/L } \\
\text { during } 24 \mathrm{~h}\end{array}$ & $\begin{array}{c}\text { Qrt4: } \\
\text { 51.5-86.5 mmol/L } \\
\text { during } 24 \mathrm{~h}\end{array}$ \\
\hline Crude & $\begin{array}{c}0.71 \\
(0.51-0.99)\end{array}$ & $\begin{array}{c}0.88 \\
(0.74-1.05)\end{array}$ & 1.00 & $\begin{array}{c}0.80 \\
(0.50-1.28)\end{array}$ & $\begin{array}{c}0.74 \\
(0.46-1.18)\end{array}$ & $\begin{array}{c}0.79 \\
(0.50-1.26)\end{array}$ \\
\hline Adjusted model 1 & $\begin{array}{c}0.72 \\
(0.51-1.01)\end{array}$ & $\begin{array}{c}0.90 \\
(0.75-1.07)\end{array}$ & 1.00 & $\begin{array}{c}0.77 \\
(0.48-1.24)\end{array}$ & $\begin{array}{c}0.76 \\
(0.47-1.21)\end{array}$ & $\begin{array}{c}0.82 \\
(0.51-1.32)\end{array}$ \\
\hline Adjusted model 2 & $\begin{array}{c}0.74 \\
(0.53-1.03)\end{array}$ & $\begin{array}{c}0.90 \\
(0.76-1.07)\end{array}$ & 1.00 & $\begin{array}{c}0.74 \\
(0.46-1.19)\end{array}$ & $\begin{array}{c}0.77 \\
(0.48-1.24)\end{array}$ & $\begin{array}{c}0.77 \\
(0.48-1.24)\end{array}$ \\
\hline Adjusted model 3 & $\begin{array}{c}0.81 \\
(0.55-1.17)\end{array}$ & $\begin{array}{c}0.98 \\
(0.79-1.21)\end{array}$ & 1.00 & $\begin{array}{c}0.88 \\
(0.52-1.50)\end{array}$ & $\begin{array}{c}0.97 \\
(0.55-1.72)\end{array}$ & $\begin{array}{c}0.97 \\
(0.53-1.77)\end{array}$ \\
\hline
\end{tabular}

$\mathrm{HR}=$ hazard ratio; $\mathrm{SD}=$ standard deviation; qrt = quartile; adjusted model 1 = age, sex, primary kidney disease; adjusted model $2=+\mathrm{DM}$ and Davies score; adjusted model $3=+$ period effect.

second explanation might be that glucose does not only exert detrimental effects on the peritoneal host defense but also on the invading microorganisms. It could well be that the risk of peritonitis is determined by the balance between harm to the peritoneal host defense on one hand and bactericidal effects on the other.

Little is known about the glucose concentrations that are necessary to facilitate bactericidal activity in humans. In vitro studies investigated different honeys and honey-equivalent sugar solutions (30-35). Among other components, the high sugar concentration and its osmolality and methylglyoxal (MG0) were identified as being responsible for the bactericidal properties of these honey substances. When we compare the sugar concentrations that were found to facilitate bacterial killing in these in vitro experiments to the glucose concentration in a PD solution, the bactericidal sugar concentrations were much higher than the maximum glucose concentrations in dialysis solutions: about $20 \%$ vs $3.86 \% / 4.25 \%$. Furthermore, the osmolality that was bactericidal in vitro was approximately twice as high as the osmolality of a $3.86 \%$ dialysis solution: $\pm 1,000 \mathrm{~m} 0 \mathrm{smol} / \mathrm{L}$ vs $483 \mathrm{m0smol} / \mathrm{L}$. However, the in vitro bactericidal concentration and osmolality might not be comparable to the exposure necessary to cause intraperitoneal bactericidal or bacteriostatic effects. In patients, RCTs assessed the effect of topical application of honey for prevention of infections and improved wound healing (36-39). It is, however, impossible to extract an effective dosage from these studies and make a comparison to glucose in the dialysis solutions.

The antibacterial properties of MGO were discovered due to its high concentrations in Manuka honey (38-42). More interestingly, MGO is one of the glucose degradation products in Dianeal, Physioneal, and icodextrin as well as in other commercially available dialysis solutions. The concentrations of MG0 are $0.5-1 \mu \mathrm{mol} / \mathrm{L}$ in Physioneal, $4-7 \mu \mathrm{mol} / \mathrm{L}$ in Dianeal and $2 \mu \mathrm{mol} / \mathrm{L}$ in icodextrin (43), suggesting that Dianeal has the highest bacteriostatic capacity. This hypothesis is supported by a previous report by Verbrugh et al. (44) which showed that Dianeal, amongst other commercially available solutions, did not support survival of Staphylococcus aureus and Staphylococcus epidermidis in vitro. In our dialysis unit, patients were treated with Dianeal between 1990 and 1997, with Dianeal or Physioneal between 1998 and 2004, and with Physioneal between 2005 and 2010. The use of icodextrin started in 1997. In our study, patients with higher glucose concentrations were more often treated with Dianeal, whereas patients with lower glucose exposure were more often treated with Physioneal and icodextrin. Therefore, our results might be influenced by a correlation between higher glucose exposure and higher MGO concentrations in our patients. This could explain the tendency of the estimates toward a protective effect of glucose exposure with respect to peritonitis risk. On the other hand, the MGO concentration differences are small and studies that compared conventional and biocompatible solutions found no difference in peritonitis risk in a meta-analysis (45).

To the best of our knowledge, we are the first to study the association between glucose exposure and severe peritonitis, Staphylococcus aureus peritonitis and peritonitis that lasted more than 14 days. The low event rate of severe and Staphylococcus aureus peritonitis limited our analyses and, although the estimates tended toward a protective effect of glucose, no association could be attributed. Higher glucose concentrations appeared to decrease the risk of a peritonitis episode that lasted longer than 14 days, but this was not statistically significant.

The present study has several strengths and weaknesses. Although demographic and clinical data and information about peritonitis episodes were collected prospectively, we retrospectively collected day-to-day dialysis schemes during the first year on PD. We are confident that a thorough review of complete original medical records was performed. However, prospective data collection would be preferred to accurately capture day-to-day glucose exposure until censoring in all patients. Because data collection was limited to the first year on PD, we are unable to draw conclusions about the influence of glucose exposure beyond the first year on PD. Although extensive adjustments were made, residual confounding

This single copy is for your personal, non-commercial use only.

For permission to reprint multiple copies or to order presentation-ready

copies for distribution, contact Multimed Inc. at marketing@multi-med.com 
cannot be excluded due to the observational design of the study. After the year 1990, 2 changes were introduced to the treatment regimen: the application of daily mupirocin at the exit site since 2001 and the use of only biocompatible fluids since 2004. However, a previous study has shown that these changes in clinical care did not significantly influence the background peritonitis rate (46). The use of strict inclusion criteria could be seen as both a limitation and a strength of the study design.

A major strength of our study is the inclusion of incident PD patients with a long-term follow-up. In addition, a novel method was used to quantify the exposure to glucose. The major advantage of this method is that it can be used for both CAPD and APD patients. Three underlying assumptions supported the calculations. First, Krediet et al. (26) found that glucose absorption was approximately $60 \%$ after a 4 -hour dwell. In addition, Smit et al. (47) showed that this was not different when dialysis solutions with different glucose concentrations were used or when patients suffered from diabetes (48). Although the calculation of glucose exposure could be improved by the substitution for $60 \%$ in the equation of the individual measured glucose exposure, the use of $60 \%$ is easy and fairly accurate (47). Second, the assumption that glucose absorption during a PD dwell follows first order kinetics has previously been established $(49,50)$. Consequently, we assumed that the geometric mean of glucose exposure in the middle of the dwell is the closest approximation of the average glucose exposure during the total dwell.

In conclusion, our study demonstrated no association between glucose exposure during the first year on PD and the subsequent time to peritonitis. This is in line with previous studies in patients. However, an overall tendency towards a protective effect of higher glucose concentrations was observed, although this was not significant in the majority of the analyses. It could well be that the risk of peritonitis is determined by the balance between the harm of dialysis solutions to peritoneal host defense on one hand and their bactericidal effects on the other. Future studies should determine whether bactericidal properties of PD solutions might have a clinically relevant function in the prevention of peritonitis.

\section{DISCLOSURES}

ATNVD was supported by a grant: 12CECPDEU1002, awarded by Baxter Healthcare. Baxter Healthcare was not involved in the collection, interpretation and analysis of the data or in the decision to write and submit this report for publication.

\section{REFERENCES}

1. Krediet RT, Struijk DG. Peritoneal changes in patients on long-term peritoneal dialysis. Nat Rev Nephrol 2013; 9:419-29.

2. Topley N. Biocompatibility of peritoneal dialysis solutions and host defense. Adv Ren Replace Ther 1996; 3:309-11.

3. Jörres A. Innovative approaches to the preservation of the peritoneal membrane: from bench to bedside. Adv Ren Replace Ther 2001; 8:164-72.

4. Mortier S, Lameire NH, de Vriese AS. The effects of peritoneal dialysis solutions on peritoneal host defense. Perit Dial Int 2004; 24:123-38.
5. Kazancioglu R. Peritoneal defense mechanisms - the effects of new peritoneal dialysis solutions. Perit Dial Int 2009; 29:198-201.

6. Coles GA, O'Donoghue DJ, Pritchard N, Ogg CS, Jani FM, Gokal R, et al. A controlled trial of two bicarbonate-containing dialysis fluids for CAPDfinal report. Nephrol Dial Transplant 1998; 13:3165-71.

7. Rippe B, Simonsen 0 , Heimburger 0 , Christensson A, Haraldsson B, Stelin $G$, et al. Long-term clinical effects of a peritoneal dialysis fluid with less glucose degradation products. Kidney Int 2001; 59:348-57.

8. Williams JD, Topley N, Craig KJ, Mackenzie RK, Pischetsrieder M, Lage C, et al. The Euro-Balance Trial: the effect of a new biocompatible peritoneal dialysis fluid (Balance) on the peritoneal membrane. Kidney Int 2004; 66:408-18.

9. Szeto CC, Chow KM, Lam CW, Leung CB, Kwan BC, Chung KY, et al. Clinical biocompatibility of a neutral peritoneal dialysis solution with minimal glucose-degradation products-a 1-year randomized control trial. Nephrol Dial Transplant 2007; 22:552-5.

10. Fan SL, Pile T, Punzalan S, Raftery MJ, Yagoob MM. Randomized controlled study of biocompatible peritoneal dialysis solutions: effect on residual renal function. Kidney Int 2008; 73:200-6.

11. Kim S, Oh J, Kim S, Chung W, Ahn C, Kim SG, et al. Benefits of biocompatible PD fluid for preservation of residual renal function in incident CAPD patients: a 1-year study. Nephrol Dial Transplant 2009; 24:2899-908.

12. Haag-Weber M, Kramer R, Haake R, Islam MS, Prischl F, Haug U, et al. LowGDP fluid (Gambrosol trio) attenuates decline of residual renal function in PD patients: a prospective randomized study. Nephrol Dial Transplant 2010; 25:2288-96.

13. Srivastava S, Hildebrand S, Fan SL. Long-term follow-up of patients randomized to biocompatible or conventional peritoneal dialysis solutions show no difference in peritonitis or technique survival. Kidney Int 2011; 80:986-91.

14. Johnson DW, Brown FG, Clark M, Boudville N, Elias TJ, Foo MW, et al. Effects of biocompatible versus standard fluid on peritoneal dialysis outcomes. J Am Soc Nephrol 2012; 23:1097-107.

15. Park SH, Do JY, Kim YH, Lee HY, Kim BS, Shin SK, et al. Effects of neutral $\mathrm{pH}$ and low-glucose degradation product-containing peritoneal dialysis fluid on systemic markers of inflammation and endothelial dysfunction: a randomized controlled 1-year follow-up study. Nephrol Dial Transplant 2012; 27:1191-9.

16. Cho Y, Johnson DW, Badve SV, Craig JC, Strippoli GF, Wiggins KJ. The impact of neutral-pH peritoneal dialysates with reduced glucose degradation products on clinical outcomes in peritoneal dialysis patients. Kidney Int 2013; 84:969-79.

17. Montenegro J, Saracho R, Gallardo I, Martinez I, Munoz R, Quintanilla $N$. Use of pure bicarbonate-buffered peritoneal dialysis fluid reduces the incidence of CAPD peritonitis. Nephrol Dial Transplant 2007; 22:1703-8.

18. Gokal R, Mistry CD, Peers EM. Peritonitis occurrence in a multicenter study of icodextrin and glucose in CAPD. MIDAS Study Group: Multicenter Investigation of Icodextrin in Ambulatory Dialysis. Perit Dial Int 1995; 15:226-30.

19. Posthuma N, ter Wee P, Donker AJ, Dekker HA, Oe PL, Verbrugh HA. Peritoneal defense using icodextrin and glucose for daytime dwell in CCPD patients. Perit Dial Int 1999; 19:334-42.

20. Chow KM, Szeto CC, Kwan BC, Pang WF, Ma T, Leung CB, et al. Randomized controlled study of icodextrin on the treatment of peritoneal dialysis patients during acute peritonitis. Nephrol Dial Transplant 2014; 29:1438-43.

21. Qi H, Xu C, Yan H, Ma J. Comparison of icodextrin and glucose solutions for long dwell exchange in peritoneal dialysis: a meta-analysis of randomized controlled trials. Perit Dial Int 2011; 31:179-88.

22. Davies SJ, Phillips L, Naish PF, Russel GI. Peritoneal glucose exposure and changes in membrane solute transport with time on peritoneal dialysis. J Am Soc Nephrol 2001; 12:1046-51.

23. Fernandez-Reyes MJ, Bajo MA, Del Peso G, Ossorio M, Diaz R, Carretero $B$, et al. The influence of initial peritoneal transport characteristics, inflammation, and high glucose exposure on prognosis for peritoneal membrane function. Perit Dial Int 2012; 32:636-44.

This single copy is for your personal, non-commercial use only. For permission to reprint multiple copies or to order presentation-ready copies for distribution, contact Multimed Inc. at marketing@multi-med.com 
24. Davies SJ, Russell L, Bryan J, Phillips L, Russell GI. Comorbidity, urea kinetics, and appetite in continuous ambulatory peritoneal dialysis patients: their interrelationship and prediction of survival. Am J Kidney Dis 1995; 26:353-61.

25. Amici G, Virga G, Da Rin G, Grandesso S, Vianello A, Gatti P, et al. Serum beta-2-microglobulin level and residual renal function in peritoneal dialysis. Nephron 1993; 65: 469-71.

26. Krediet RT, Boeschoten EW, Zuijderhoudt FMJ, Arisz L. The relationship between peritoneal glucose absorption and body fluid loss by ultrafiltration during continuous ambulatory peritoneal dialysis. Clin Nephrol 1987; 27:51-5.

27. Davies SJ, Bryan J, Phillips L, Russell GI. Longitudinal changes in peritoneal kinetics: the effects of peritoneal dialysis and peritonitis. Nephrol Dial Transplant 1996; 11:498-506.

28. Verger C, Duman M, Durand PY, Veniez G, Fabre E, RyckelynckJP. Influence of autonomy and time of home assistance on the prevention of peritonitis in assisted automated peritoneal dialysis patients. An analysis of data from the French Language Peritoneal Dialysis Registry. Nephrol Dial Transplant 2007; 22:1218-23.

29. Bieber SD, Burkart J, Golper TA, Teitelbaum I, Mehrotra R. Comparative outcomes between continuous ambulatory and automated peritoneal dialysis: a narrative review. AJKD 2014; 63:1027-37.

30. Cooper RA, Molan PC, Harding KG. The sensitivity to honey of gram-positive cocci of clinical significance isolated from wounds. J Appl Microbiology 2002; 93:857-63.

31. Cooper RA, Halas E, Molan PC. The efficacy of honey in inhibiting strains of Pseudomonas aeruginosa from infected burns. J Burn Care Rehabil 2002; 23:366-70.

32. Merckoll P, Jonassen T0, Vad ME, Jeansson SL, Melby KK. Bacteria, biofilm and honey: a study of the effects of honey on 'planktonic' and biofilm-embedded chronic wound bacteria. Scand J Infect Dis 2009; 41:341-7.

33. Kwakman PH, te Velde AA, de Boer L, Speijer D, Vandenbroucke-Grauls CM, Zaat SA. How honey kills bacteria. FASEB J 2010; 24:2576-82.

34. Kwakman PH, de Boer L, Ruyter-Spira CP, Creemers-Molenaar T, Helsper JP, Vandenbroucke-Grauls CM, et al. Medical-grade honey enriched with antimicrobial peptides has enhanced activity against antibiotic-resistant pathogens. Eur J Clin Microbiol Infect Dis 2011; 30:251-7.

35. Kwakman PH, van den Akker JP, Güçlü A, Aslami H, Binnekade JM, de Boer $\mathrm{L}$, et al. Medical-grade honey kills antibiotic-resistant bacteria in vitro and eradicates skin colonization. Clin Infect Dis 2008; 46:1677-82.

36. Moore OA, Smith LA, Campbell F, Seers K, McQuay HJ, Moore RA. Systematic review of the use of honey as a wound dressing. BMC Complement Altern Med 2001; 1:2.

37. Johnson DW, van Eps C, Mudge DW, Wiggins KJ, Armstrong K, Hawley CM, et al. Randomized, controlled trial of topical exit-site application of honey (Medihoney) versus mupirocin for the prevention of catheterassociated infections in hemodialysis patients. J Am Soc Nephrol 2005; 16: 1456-62.

38. Kwakman PH, Muller MC, Binnekade JM, van den Akker JP, de Borgie $\mathrm{CA}$, Schultz MJ, et al. Medical-grade honey does not reduce skin colonization at central venous catheter-insertion sites of critically ill patients: a randomized controlled trial. Crit Care 2012; 16: R214.

39. Johnson DW, Badve SV, Pascoe EM, Beller E, Cass A, Clark C, et al. Antibacterial honey for the prevention of peritoneal-dialysis-related infections (HONEYPOT): a randomised trial. Lancet Infect Dis 2014; 14:23-30.

40. Atrott J, Henle T. Methylglyoxal in Manuka honey-correlation with antibacterial properties. Czech J Food Sci 2009; 27:S163-5.

41. Mavric E, Wittmann $\mathrm{S}$, Barth $\mathrm{G}$, Henle T. Identification and quantification of methylglyoxal as the dominant antibacterial constituent of Manuka (Leptospermum scoparium) honeys from New Zealand. Mol Nutr Food Res 2008; 52:483-9.

42. Adams CJ, Manley-Harris M, Molan P. The origin of methylglyoxal in New Zealand manuka (Leptospermum scoparium) honey Carbohydr Res 2009; 344:1050-3.

43. SchalkwijkCG, ter Wee PM, Teerlink T. Reduced 1,2-dicarbonyl compounds in bicarbonate/lactate-buffered peritoneal dialysis (PD) fluids and PD fluids based on glucose polymers or amino acids. Perit Dial Int 2000; 20:796-8.

44. Verbrugh HA, Keane WF, Conroy WE, Peterson PK. Bacterial growth and killing in chronic ambulatory peritoneal dialysis fluids. J Clin Microbiol 1984; 20:199-203.

45. Cho Y, Johnson DW, Craig JC, Strippoli GF, Badve SV, Wiggins KG. Biocompatible dialysis fluids for peritoneal dialysis. Cochrane Database Syst Rev 2014; 27: CD007554.

46. Van Esch S, Krediet RT, Struijk DG. 32-years of experience of peritoneal dialysis-related peritonitis in a university hospital. Perit Dial Int 2014; 34:162-70.

47. Smit W, Langedijk MJ, Schouten N, van den Berg N, Struijk DG, Krediet RT. A comparison between $1.36 \%$ and $3.86 \%$ glucose dialysis solution for the assessment of peritoneal membrane function. Perit Dial Int 2000; 20:734-41.

48. Smit W, van Esch S, Struijk DG, Krediet RT. Free water transport in patients starting with peritoneal dialysis: a comparison between diabetic and non diabetic patients. Adv Perit Dial 2004; 20:13-7.

49. Garred LJ, Canaud B, Farrell PC. A simple kinetic model for assessing peritoneal mass transfer in chronic ambulatory peritoneal dialysis. ASAIO J 1983; 6:131-7.

50. Krediet RT, Boeschoten, Zuijderhoudt FMJ, Strackee J, Arisz L. Simple assessment of the efficacy of peritoneal transport in continuous ambulatory peritoneal dialysis patients. Blood Purif 1986; 4:194-203.

This single copy is for your personal, non-commercial use only.

For permission to reprint multiple copies or to order presentation-ready 